\title{
Sexo, Gênero, Sexualidade: Via(da)gens* em Conceitos
}

Antoniel dos Santos Gomes Filho ${ }^{1}$; Cícero Edinaldo dos Santos ${ }^{2}$; Lielton Maia Silva ${ }^{3}$

\begin{abstract}
Resumo: O objetivo desse texto é realizar uma via(da)gem (sem ponto de chegada) dialógica nos conceitos de sexo, gênero e sexualidade, a partir de alguns textos oriundos das teorias feministas, sociais e queer/transviadas, advindos tanto do eixo euro-americano como das produções nacionais, promovendo assim um diálogo entre esses saberes e dizeres com os processos educacionais no âmbito escolar. Utilizando-se da abordagem qualitativa com base numa revisão bibliográfica, produzimos uma discussão que tenta responder as seguintes questões, a saber: Quais são as ideias e ideais de sexo, gênero e sexualidade embasados nas hetero-normas? Sócio-historicamente de onde surgem ou se organizam essas ideias e ideais?
\end{abstract}

Palavras-Chave: Sexo, Gênero, Sexualidade. Educação. Estudos Transviados.

* (Brasil) Designação pejorativa, preconceituosa e depreciativa para se referir aos homossexuais do sexo masculino.

\section{Sex, Gender, Sexuality: Viadagens* in Concepts}

Abstract: The aim of this text is to carry out a viadagem* dialogue (without a point of arrival) dialogic in the concepts of sex, gender and sexuality, based on some texts derived from the feminist, social and queer / transvestite theories, arising both from the Euro-American axis and of national production, thus promoting a dialogue between these knowledge and sayings with the educational process in schools. Using a qualitative approach based on a literature review, we produce a discussion that attempts to answer the following questions, namely: What are the ideas and ideals of sex, gender and sexuality grounded in hetero-standards? Socio-historically, where do these ideas and ideals come from or are they organized?

Keywords: Sex, Gender, Sexuality. Education. Transversed Studies.

* (Brazil) Pejorative, biased and derogatory designation to refer to homosexual men.

\section{Introdução}

$$
\begin{array}{r}
\text { Podemos utilizar o conhecimento científico para nos ajudar a tomar a decisão, mas } \\
\text { só nossas crenças sobre gênero - e não sobre as ciências - podem definir nosso } \\
\text { sexo. } \\
\text { (FAUSTO-STERLING, 2002, p. 15). }
\end{array}
$$

A Educação Brasileira ainda é interpelada por comportamentos, valores e ideais que priorizam a binaridade do sexo e gênero (masculino e feminino) e a heterossexualidade. Tais interpelações atravessam o processo de ensino-aprendizagem nas escolas e universidades, bem como nas (re)ações de outras instituições sociais (família, igreja, etc).

\footnotetext{
**As ideias iniciais desse texto foram apresentados na III Semana de Humanidades da UERN, realizada no período de 29 de novembro a 2 de dezembro de 2016, Mossoró-RN, sendo aqui revisadas e ampliadas.

${ }^{1}$ Mestrando em Educação Brasileira na Universidade Federal do Ceará (UFC), vinculado à Linha de História da Educação Comparada (LHEC). E-mail: antoniel.historiacomparada@gmail.com

${ }^{2}$ Doutorando em Educação Brasileira na Universidade Federal do Ceará (UFC), vinculado à Linha de História da Educação Comparada (LHEC). E-mail: cicero.edinaldobb.edinaldo@gmail.com

${ }^{3}$ Docente do curso de Psicologia da Faculdade Vale do Salgado (FVS). Especialista em Saúde Mental pela Universidade Católica Dom Bosco. E-mail: lieltonmaia@fvs.edu.br
} 
Nossas instituições educacionais são locais onde as "pedagogias da sexualidade" (LOURO, 2000) são solicitadas a todo o momento para ensinar aos corpos como estes devem ser ou estar no mundo, tendo como referência o pênis e a vagina, como partes do corpo que "organizam" o curso inteligível da vida social e sexual.

De acordo com Gomes Filho et al. (2015) quando se propõe falar sobre questões de sexo, gênero e sexualidade no âmbito escolar, na grande maioria das vezes, esses debates possuem um grande enfoque biomédico; fala-se sobre as Doenças Sexualmente Transmissíveis e suas formas de prevenção, sobre as formas de reprodução e meios contraceptivos, sobre os aspectos fisiológicos do corpo, etc. Há dessa maneira uma redução da sexualidade a tais aspectos, o que deixa de lado outros debates de cunho histórico, social e filosófico, produzindo assim uma legitimação do sexo, gênero e da sexualidade como algo dotado de uma natureza, uma essência inerente ao ser humano.

Os conceitos de sexo, gênero e sexualidade desde meados do século XX vêm sendo (re)criados e disputados por diversos campos do saber, como: as ciências médicas e biológicas, e as ciências humanas e sociais (história, filosofia, sociologia, educação, etc.). Nesse sentido podemos observar que esses conceitos são alvos de disputa de saber-poder, seguindo aqui os referenciais foucaultianos.

De acordo com Le Breton (2002, p. 14) "La concepición que se admite con mayor frecuencia [sobre o corpo] encontra su formulación en la anatomofisiología, es decir, en el saber que proviene de la biología y de la medicina.". Nesse sentido, percebemos que os referenciais biomédicos possuem no campo social uma legitimidade para dizer "verdades" sobre o corpo e tudo que se refere a ele. Essa tomada discursiva sobre os assuntos do corpo humano por parte dos olhares biomédicos pode ser um indicador de como, na escola, a disciplina/matéria de biologia é o local para se aprender sobre o corpo e suas funções anatômicas e fisiológicas.

O moderno paradigma biomédico que se consolida a partir de meados dos anos 1950 tende a alocar os sexos e as sexualidades como algo natural inerente a biologia, sendo que, para aqueles/as cuja natureza tenha "errado" em algum momento, os saberes biomédicos lá estariam para fazer as correções necessárias, tais como nas crianças intersexuais ou nos/as transexuais. Vale ressaltar que esse paradigma tem suas origens históricas na virada dos séculos XVIII e XIX, como pode ser visto através nos textos: La construción del sexo: cuerpo y género desde 
Id on Line Revista Multidisciplinar e de Psicologia

Id on Line Multidisciplinary and Psycology Journal

los griegos hasta Freud, de Thomas Laqueur (1994) e O corpo e a sexualidade, de Jeffrey Weeks (2000).

Nesse mesmo período, os movimentos sociais feministas de segunda onda, como diz Rubin (2003, p. 158) buscavam um modo, “[...] uma ideia de como pensar e entender a opressão das mulheres.". Esse período foi atravessado pelo paradigma marxista, onde podemos situar brasileira Heleieth I. B. Saffioti como uma das influenciadas por esse modelo analítico. Mas como foi percebido por Rubin e outras teóricas feministas, só era possível avançar dentro de um paradigma marxista, sabendo que ele, embora útil, possuía limitações no que diz respeito a gênero e sexo. Desse modo, para além do entendimento acerca da opressão das mulheres, outras pautas foram introduzidas, tanto em âmbito politico como em termos teórico-metodológicos. Outras vertentes de feminismo surgiram, tais como o feminismo negro e o feminismo lésbico.

Os anos 1960-70, em todo o mundo ocidental, foram marcados pelos novos movimentos sociais, além do feminista, os movimentos gays e lésbicos, o movimento negro, etc. emergiam com grande força no cenário ocidental. No Brasil, os primeiros grupos formados por homossexuais organizaram-se em fins dos anos 70 no período da ditadura militar (FACCHINI, 2002). De acordo com Fry e MacRae (1987) quando pensamos nos movimentos sociais homossexuais brasileiros, e estendendo para o feminismo, a circulação de ideias e conceitos de sexo, gênero e sexualidade discutidos no território brasileiro estavam ligadas aos discursos americanos, uma vez que muitos brasileiros foram formados nesses espaços.

Acreditamos que os conceitos sobre sexo, gênero e sexualidade desde a década de 70 até os dias atuais, cunhados no eixo euro-americano, tem sido absorvido e discutido, (re)produzidos e modificados nos países fora desse eixo, como é o caso do Brasil. Atentamos ao leitor que na atualidade há instaurado um grande debate sobre a circulação e validação de epistemologias produzidas ao sul global como pode ser visto nas produções dos estudos póscoloniais e subalternos ${ }^{1}$, inclusive quando se pensa e discute as categorias aqui apresentadas.

Nesse estudo estamos preocupados em pensar na circulação e produção dos conceitos de sexo, gênero e sexualidade que foram analisados e utilizados das mais diversas formas nos movimento feminista e homossexuais ocidentais nos últimos quarenta anos (1970-2010). A marcação/delimitação temporal apresentada aqui não é indicativa de uma linearidade analítica

\footnotetext{
${ }^{1}$ Para um aprofundamento sobre o tema ver: SANTOS, B. S.; MENESES, M. P. (Orgs.). Epistemologias do Sul. São Paulo: Editora Cortez, 2010.
} 
Id on Line Revista Multidisciplinar e de Psicologia

Id on Line Multidisciplinary and Psycology Journal

dos conceitos, ou mesmo de uma escrita que sinalize os conceitos em seus tempos-espaços, já que a produção, a reprodução, a utilização, a atribuição de sentidos, etc. sempre estiveram atrelados a processos de continuidade e rupturas.

Portanto, nosso objetivo é realizar uma via(da)gem (sem ponto de chegada) dialógica nos conceitos de sexo, gênero e sexualidade a partir de alguns textos oriundos das teorias feministas, sociais e queer/transviadas, advindas tanto do eixo euro-americano como das produções nacionais, promovendo assim um diálogo entre esses saberes e dizeres produzidos no Brasil e nos grandes centros nortistas-ocidentais.

Nossos itinerários metodológicos possuem abordagem qualitativa (GAMSON, 2006) com base numa revisão bibliográfica (HOHENDORFF, 2014). São alguns textos apresentados nessa via(da)gem: Gênero: uma categoria útil para a análise histórica (1990), de Joan Scott; Problemas de gênero: feminismo e subversão da identidade (2008), de Judith Butler e Manifesto contrassexual (2014) de Beatriz Preciado, Um corpo estranho: ensaios sobre sexualidade e teoria queer (2015), de Guacira Lopes Louro, Na escola se aprende que a diferença faz a diferença (2011) e O que pode uma teoria? estudos transviados e a despatologização das identidades trans (2014), de Berenice Bento, além de outros textos que possam nos ajudar a debater sobre as diversas questões que surgem nessa seara dos estudos dos sexos, dos gêneros e das sexualidades.

Informamos ao leitor desse texto que ele é antes de tudo fluido e mutável, pode ser apagado, reescrito, (re)utilizado, jogado fora ou dentro de novas configurações textuais, pode ou não ter função, sendo esses usos da ordem do leitor. É nesse devir, devir a ser texto, que apresentamos esse texto, ou artigo (como queiram denominar), que é antes de qualquer coisa uma forma de fluxo de olhares mutáveis sobre os processos de produção (sociais e subjetivos) do sexo, do gênero e da sexualidade.

\section{Via(da)gens em Conceitos: Sexo, Gênero e Sexualidade}

Diversos são os pontos de partida para essa via(da)gem de discutir e entrelaçar os diversos conceitos formulados, disputados, esquecidos, relembrados, etc... das ciências humanas, sociais e biológicas sobre os sexos, os gêneros e as sexualidades, e seus 
Id on Line Revista Multidisciplinar e de Psicologia

Id on Line Multidisciplinary and Psycology Journal

entrelaçamentos com a educação, e em especial a educação brasileira tomada em seus espaços formais de escolarização.

Bourdieu e Passeron (1975) no livro: A reprodução: elementos para uma teoria do sistema de ensino (SE), afirmam que os sistemas de ensino estão correlacionados as dinâmicas sociais (externas aos muros da escola) e no lugar de serem meios para democratização, reproduz as diferenças encontradas na sociedade. Desse modo, a escola e o SE institucionalizado não é meio para uma mudança social, de forma equitativa, é apenas mais uma instituição total responsável pela reprodução e legitimação de um arbitrário cultural de uma classe dominante, e uma desqualificação das práticas das classes menos abastardas. Nas teorias da educação o pensamento desses autores está situado numa matriz crítico reprodutivista, a partir deles podemos pensar na escola como um local de reprodução das ideias e ideais de sexo, gênero e sexualidade que tem por base as hetero-normas, que fundam/embasam a sociedade ocidental.

E quais são as ideias e ideais de sexo, gênero e sexualidade com base nas hetero-normas? E, sócio-historicamente de onde surgem, ou se organizam essas ideias e ideais?

De acordo com Weeks (2000) as questões relativas à sexualidade sempre foi pauta das sociedades ocidentais, mas até fins do século XVIII e início do século XIX tais questões estavam mais ligadas à religião e a filosofia, mas a partir da metade do século XIX, o comportamento sexual tem sido tomado como uma preocupação dos especialistas da medicina, tanto que nos fins do século torna-se uma disciplina, a sexologia, que coloca a sexualidade para além do campo privado, colocando-a no espaço público como uma questão política. Continua o autor apresentando os estudos de Richard von Krafft-Ebing de fins do século XIX que descreve o sexo como algo natural e instintivo, instaurando-o assim um olhar essencialista.

Weeks utiliza-se de uma abordagem construtivista ou construtivismo social para abordar os corpos de modo relativo, levando em consideração as construções sócio-históricas, em outras palavras, busca-se na abordagem construtivista investigar como as sociedades em seus temposespaços construíram saberes sobre o sexo e a sexualidade dos sujeitos, e se há na contemporaneidade resquícios e rupturas dessas ideias. Weeks propõe em seu texto usos para os termos sexo, gênero e sexualidade.

Tomaremos de empréstimo inicial sua definição para sexualidade "[...] como uma descrição geral para a série de crenças, comportamentos, relações e identidades socialmente construídas e historicamente modeladas [...]”. Frente a esse conceito pensamos a sexualidade 
como uma grande "mistura" do que é dito e tido para as mais diversas instâncias do corpo, seus usos e suas práticas, que atravessa as construções sociais e subjetivas dos indivíduos e grupos.

Ainda nessa breve incursão sobre os olhares de especialistas do campo das ciências biomédicas, podemos trazer para a discussão as formulações de John Money desenvolvidas nos anos de 1955, que segundo Preciado (2014) já abordavam aspectos construtivistas, antes mesmo deste ser formulado nas teorias feministas. Segundo Preciado a teoria de atribuição de sexo, produzida pelo professor de psicopediatria do hospital universitário John Hopkins em Nova York, levava em consideração as análises cromossômicas e a estética dos órgãos genitais, para definir qual o sexo de uma criança intersexual. Para ele o gênero poderia ser modificável até os primeiros 18 meses de idade. Preciado relata que todos os movimentos de Money em torno da atribuição de um sexo para os bebês e crianças intersexuais estão ligados a "um sistema de representação sexual heterocentrado", assim nossos corpos são visualizados ou como homem, ou como mulher, porque o pênis e a vagina são a fonte dessa representação. Esse sistema se embasa numa prática heterossexual, pois:

\begin{abstract}
Os processos de construção de um canal vaginal nas meninas intersexuais não são simplesmente destinados a produção de um órgão. Dirigem-se, sobretudo, à prescrição das práticas sexuais, posto que se define como vagina única e exclusivamente aquele orifício que pode receber um pênis adulto. [...] Se o recém-nascido intersexual dispõe de uma configuração cromossômica que possui pelo menos um cromossomo Y, será considerado geneticamente masculino. Nesse caso, o problema consiste em saber se o chamado "tecido fálico" é suscetível ou não de reagir positivamente a um tratamento hormonal à base de andrógenos que aumente o tamanho do microfalo ou do micropênis. Mas o corpo do bebê se enfrenta com um juízo visual que relegará as análises cromossômicas à categoria de verdades secundárias. Os critérios de "longitude", de "tamanho" e de "aparência normal" dos genitais substituirão os critérios que regem os testes cromossômicos (PRECIADO, 2014, p. 135-136).
\end{abstract}

Caso o bebê intersexual cromossomicamente XY, ou seja, considerado masculino, não reaja aos tratamentos para que seu pênis num futuro tenha uma "aparência normal”, para Money este bebê deve ser criado como uma menina e não como um menino, como diz Preciado, as definições de masculino e feminino em Money estão correlacionadas à estética dos órgãos sexuais, independentemente de suas capacidades de reprodução.

As crenças, valores e construções sociais para o que é ser homem ou mulher são solicitados pelas ciências biomédicas para definir o sexo de um ser humano que não apresenta visualmente um pênis e uma vagina, mesmo este sendo possuidor de um sexo geneticamente identificável. Esse pensamento se instaura num dualismo. Não se ver outra possibilidade, outra 
Id on Line Revista Multidisciplinar e de Psicologia

Id on Line Multidisciplinary and Psycology Journal

saída, a não ser enquadrar esses corpos como do sexo masculino ou feminino, mesmo que estes possam variar, como diz Fausto-Sterling (1993) no seu artigo Los cinco sexos.

II

Como observado às construções entorno do conceito de sexo, gênero e sexualidade já estavam em cena antes mesmo dos movimentos feministas colocasse mais enfaticamente a discussão na sociedade. Não queremos aqui definir uma gênese para os conceitos, mas acreditamos que nessa via(da)gem é necessário que passemos por esses caminhos a fim de alcançar o objetivo proposto e perceber como essas produções biomédicas e psi (psicologia, psicanálise e psiquiatria) foram responsáveis pela patologização de sexualidades. Assim, trataremos agora de entender como os movimentos feministas a partir dos anos 1960-70 e posteriormente o movimento queer/transviado teorizaram o sexo e o gênero, por isso:

\footnotetext{
A produção de masculinidades, em quaisquer de suas formas, implica uma relação com o feminismo como grande força política do século XX, que alterou profundamente a ordem do gênero no mundo ocidental moderno. $\mathrm{O}$ empenho com o qual o discurso feminista designou o corpo feminino como sendo produto de uma história política e não simplesmente de uma história natural deve ser celebrado como o início de uma das maiores rupturas epistemológicas do século XX (VALE, 2006, P. 61 , grifos do autor).
}

A produção teórica feminista além de promover contestações sobre as relações sociais entre homens e mulheres na sociedade também foi responsável por um resgate histórico-político da figura da mulher, contribuindo para redimensionar a história oficial, retirando o ar de naturalidade e essencialismo das construções sociais destinadas ao feminino e para o masculino.

No artigo de Maria Odila Leite da Silva Dias intitulado: Novas subjetividades na pesquisa histórica feminista: uma hermenêutica das diferenças; a autora nos mostra que os estudos feministas constituem-se como críticas as diversas formas de produção das relações sociais que hierarquizam socialmente as mulheres e os homens, assim, “[...] os estudos feministas propõem uma redefinição dos processos de subjetividade, uma crítica ao conceito de identidade, bem como ao conceito da própria racionalidade no mundo contemporâneo, que se volta para o passado a fim de se reencontrar, devidamente relativizada, no presente." Para a autora, um dos principais objetivos dos estudos feministas consiste em criticar totalidades e 
Id on Line Revista Multidisciplinar e de Psicologia

Id on Line Multidisciplinary and Psycology Journal

estereótipos construídos socialmente e que se propõem universais. A autora realiza uma crítica a trabalhos que se propõe a formulação de uma história das mulheres, afirmando que tais produções promovem um discurso normativo sobre as mesmas, uma vez que, “[...] o feminino foi excluído do discurso e aprisionado por ele; genérico e sem condição de explicitação a não ser no plano da especificidade histórica, da sua concretude, da sua negação, enquanto categoria universal" (DIAS, 1992 apud DIAS, 1994, p. 374).

Para sair dessa vertente de uma história universal sobre as mulheres a autora propõe um distanciamento de um pensamento sobre o ser humano (séc. XVII e XVIII) que está sobre a fala do "Sujeito Abstrato Universal", e coloca o desafio da pesquisa sobre as identidades femininas fora desse pensamento de universalidade, o que promoveria "subjetividades plurais". Os estudos feministas no lugar de buscar conceitos totalizantes e universais buscam as questões contextuais, históricas e relativistas sobre as diversas mulheres. Nas palavras da autora “[...] trata-se de historicizar os próprios conceitos com que se tem de trabalhar, tais como reprodução, família, público, particular, cidadania e sociabilidades, a fim de transcender definições estáticas e valores culturais herdados como inerentes a uma natureza feminina." (DIAS, 1994, p. 375). Nesse sentido podemos pensar no próprio conceito de gênero, um conceito muito utilizado nos estudos feministas, e utilizados de diversas maneiras.

O texto da historiadora Joan Scott, intitulado: Gênero: uma categoria útil para análise histórica; apresenta como o termo gênero foi utilizado nos estudos feministas. Para Joan Scott (1990) o uso do termo gênero ao longo de suas diversas utilizações no campo das ciências históricas e sociais, e nos estudos feministas foi atravessado por três modos de significação, sendo estes: (01) nos anos 1980, o termo gênero foi em muitos livros um substituto do termo mulher, sua utilização deu-se, pois o gênero demonstrava um caráter mais "neutro", ou seja, retirava conotações politicas que o termo mulher apresentava. Frente a essa questão a autora aponta que essa utilização estava correlacionada a uma busca por legitimidade acadêmica dos estudos feministas na referida década; (02) o termo gênero foi utilizado como meio indicativo de que o estudo das mulheres também eram os estudos dos homens, e que não se poderia pensar o estudo de um sem o outro; e, (03) o termo gênero se refere às relações sociais entre os sexos. $\mathrm{O}$ gênero nesse momento afasta-se de possíveis indicadores biológicos, alocando também as questões de sexo e sexualidade no plano social. Logo, o termo é sinônimo de indicação de construções históricas sobre os papéis sociais de mulheres e homens na sociedade. Essa 
Id on Line Revista Multidisciplinar e de Psicologia

Id on Line Multidisciplinary and Psycology Journal

utilização do termo gênero proporciona que os pesquisadores busquem nas relações sociais os processos de subjetivação de homens e mulheres, sendo que o sexo pode está incluído nessas análises, não como sendo o fator determinante ou de origem, mais também como uma construção social.

Scott $(1990$, p. 7) ressalta que todos esses usos do termo gênero se referem apenas “[ [..] aos domínios - tanto estruturais quanto ideológicos - que implicam em relações entre os sexos.” Mas a autora nos alerta para uma questão fundamental de análise, quando nos lembra de que o gênero mesmo indicando as relações sociais entre os sexos, não aponta e não diz como ocorre a construção dessas relações, como funcionam ou como mudam, desse modo, o gênero continua associado ao referente mulher.

Scott (1990, p. 19) apresenta o gênero como uma categoria teórica analítica que surge no final do século XX, assim, em muitos trabalhos históricos que versam sobre teorias sociais que datam do século XVIII até o começo do século XX, não trazem tal perspectivas, mas em “[...] algumas dessas teorias construíram a sua lógica sob analogias com a oposição masculino/feminino, outras reconheceram uma "questão feminin", outras ainda preocuparamse com a formação da identidade sexual subjetiva, mas o gênero, como o meio de falar de sistemas de relações sociais ou entre os sexos, não tinha aparecido." No contexto de produção historiográfica dos estudos feministas do final do século XX, Dias aponta que tais estudos consistem,

[...] basicamente em delimitar o lugar, a situação, a posição relativa do grupo social ou mulheres a serem estudadas no conjunto de uma certa sociedade. [E aponta que metodologicamente que] $\mathrm{O}$ primeiro passo consiste em assumir a temporalidade histórica do tema e a partir daí proceder à construção do objeto de estudo, delimitando e problematizando todas as balizas do conhecimento relativas a estas mulheres, até mesmo o próprio conceito de mulher ou a categoria mulheres (DIAS, 1994, p. 376).

Quando observamos e estudamos as produções dos fins do século XX e do século XIX, é perceptível que há uma busca por definições dos conceitos de mulher ou a categoria mulher, como ressaltado por Dias. Assim, a categoria mulher numa perspectiva universal, foi bastante questionada e criticada, como podemos ver na produção de Judith Butler (2008) no texto Problemas de gênero: feminismo e subversão da identidade. Essa crítica abriu espaços para novas identidades que incorporam o feminino, ou seja, o sistema sexo/gênero/desejo que estava mais próxima de uma ótica dual biológica e médica, volta-se para as construções sociais do que 
Id on Line Revista Multidisciplinar e de Psicologia

Id on Line Multidisciplinary and Psycology Journal

é ser mulher ou ser homem na sociedade. Diante disso, novas sujeitas do feminino surgem além de uma mulher universal. Mulheres negras, Travestis, Transexuais, Intersexuais, Drags e outros sujeitos ininteligíveis adentraram no feminismo, ou melhor, nos feminismos.

Quando o status construído do gênero é teorizado como radicalmente independente do sexo, o próprio gênero torna-se um artifício flutuante, com a consequência de que um homem e masculino podem, com igual facilidade, significar tanto um corpo feminino como masculino, e mulher e feminino, tanto um corpo masculino como um feminino (BUTLER, 2008, p. 24-25, grifos da autora).

Nesse encaminhamento, podemos pensar nas identidades de gênero, ou seja, as reivindicações por determinado gênero sem necessariamente pertencer a um sexo biológico que segue uma ordem inteligível, bio-homem-gênero masculino, bio-mulher-gênero feminino. É a partir dessa virada nos estudos feministas e de gênero que há uma valorização dos estudos do e sobre o cotidiano e das histórias de vida de gays, lésbicas, travestis, transexuais, mulheres negras e dos demais sujeitos ininteligíveis que foram apagados de uma história oficial masculina, que apagou as diversas formas de exclusão, discriminação, preconceito, sexíssimo, homofobia e outras formas de violência vivenciadas e experienciadas por esses sujeitos e grupos organizados.

III

É nesse mesmo período que a Teoria e Movimento Queer surge como lugar de produção do conhecimento dessas experiências dissidentes. Ou seja, a teoria Queer "sugere que o estudo das "outras" sexualidades humanas não deveria ser um estudo sobre as minorias, mas uma investigação acerca dos conhecimentos e das práticas sociais que organizam a sociedade em tempos históricos variados, "sexualizando" desejos, atos, cultura e instituições sociais." (GOMES FILHO; SANTOS, 2015, p. 161).

O novo movimento queer voltava sua crítica à emergente heteronormatividade, dentro do qual gays e lésbicas normalizados são aceitos, enquanto na linha vermelha da rejeição social é pressionada por outras, aqueles e aquelas considerados anormais ou estranhos por deslocarem o gênero ou não enquadrarem suas vidas amorosas e sexuais no modelo heterorreprodutivo. O queer, portanto, não é uma defesa da homossexualidade, e a recusa dos valores morais violentos que instituem e fazem valer a linha vermelha da abjeção, essa fronteira rígida entre os que são socialmente 
aceitos e os que são relegados à humilhação e ao desprezo coletivo (MISKOLCI, 2013, p. 25).

Nos anos 1990 a Teoria Queer espalha-se por outros centros universitários juntamente com o ativismo, sendo então sua discussão ampliada e problematizada (GOMES FILHO, 2016). No Brasil a entrada dos Estudos Queer dar-se através dos estudos no campo da educação, em especial pela produção da Prof ${ }^{a}$. Guacira Lopes Louro. Em seu ensaio intitulado: Um corpo estranho: ensaios sobre sexualidade e teoria queer (2015, p. 39), a autora nos lembra que o queer surge como uma crítica as vertentes dos movimentos homossexuais (gays e lésbicos) que propunham uma politica da identidade em décadas anteriores, assim, "[...] queer significa colocar-se contra a normalização - venha de onde vier. Seu alvo mais imediato de oposição é, certamente, a heteronormatividade compulsória da sociedade; mas não escaparia de sua crítica a normalização e estabilidade proposta pela política de identidade do movimento homossexual dominante.".

Outra teórica que podemos salientar para discutir sobre teoria queer no Brasil, mais especificamente sobre as traduções e torções desses conceitos é a Prof ${ }^{a}$ Berenice Bento, que utiliza a terminologia Estudos Transviados (BENTO, 2014) como uma tradução cultural idiossincrática para os estudos queer. Indaga Berenice Bento:

\footnotetext{
Qual a potência do queer na sociedade brasileira? Nenhuma. Se eu falo transviado, viado, sapatão, traveco, bicha, boiola, eu consigo fazer com que meu discurso tenha algum nível de inteligibilidade local. O próprio nome do campo já introduz algo de um pensamento colonizado que não me agrada de jeito nenhum. Nos meus textos, eu começo falando de estudos/ativismos transviados, abro aspas e digo "tradução cultural (idiossincrática) para teoria queer" e sigo. (Berenice Bento - Entrevista concedida a Padilha e Facioli, 2015, p.146).
}

Nesse sentido, para a autora é necessário que busquemos uma forma brasileira de ver e pensar os estudos queer, e os estudos sobre sexo, gênero e sexualidade como um todo, vendo os referenciais e as epistemologias produzidas localmente e como tais produções criam uma inteligibilidade com a realidade social. Inclusive no que diz respeito às questões de homofobia e preconceito no âmbito escolar. 
Id on Line Revista Multidisciplinar e de Psicologia

Id on Line Multidisciplinary and Psycology Journal

IV

Os números de violência contra Lésbicas, Gays, Bissexuais, Travestis, Transexuais e Transgênero (LGBTs) no Brasil são alarmante, como é apontado pelo antropólogo Luis Mott:

Hoje no Brasil, a cada 27 horas um gay, travesti, transexual ou lésbica é brutalmente assassinado, vítima da homofobia - ódio à homossexualidade. Nosso pais é campeão mundial nestes crimes: nas últimas três décadas, 4.648 homicídios foram documentados. Metade dos assassinatos registrados ao redor do mundo ocorre em nosso pais. Matam-se muitíssimo mais LGBTs no Brasil do que nos 78 países onde ser gay ainda é crime (MOTT, 2015, s/p).

Retratando os dados sobre homofobia na escola buscamos nas pesquisas de Miriam Abramovay et al. (2004) um lugar de observação sobre as agressões (físicas, psíquicas, econômicas, etc...) sofridas por aqueles que têm outras formas de viver a sexualidade para além das hetero-normas, lembrando que muitas vezes tais violências são tomadas como "naturais" e muitas vezes não entendidas como tal. Dentre as diversas definições para o conceito de homofobia, nos aproximamos com a visão de Borrillo, quando afirma:

\begin{abstract}
A homofobia pode ser definida como a hostilidade geral, psicológica e social contra aquelas e aqueles que, supostamente, sentem desejo ou têm práticas sexuais com indivíduos de seu próprio sexo. Forma especifica de sexismo, a homofobia rejeita, igualmente, todos aqueles que não se conformam com o papel predeterminado para seu sexo biológico. Construção ideológica que consiste na promoção constante de uma forma de sexualidade (hetero) em detrimento de outra (homo), a homofobia organiza uma hierarquização das sexualidades e dessa postura, extrai consequências políticas (BORRILLO, 2010, p. 34).
\end{abstract}

Frente a essa definição podemos pensar nas "pedagogias da sexualidade" (LOURO, 2000) tanto nas instituições escolares como na família, e como os valores heterossexuais se instauram numa ordem hierárquica superior as homossexualidades, tanto que:

Quando se pergunta aos alunos sobre quais pessoas ele não gostaria de ter como seu colega de classe, aproximadamente $1 / 4$ dos alunos indicam que não gostariam de ter um colega homossexual, sendo que os percentuais extremos dessas respostas ficam entre $30,6 \%$ (Fortaleza) e 22,6\% (Belém), o que corresponde em números absolutos a 112.477 (Fortaleza) e a 43.127 (Belém). Ressalta-se que os jovens do sexo masculino, em qualquer capital analisada, rechaçam com maior intensidade a homossexualidade. Por exemplo, em Porto Alegre, enquanto $42 \%$ dos rapazes indicam tal preconceito, no caso das moças, baixa para $13 \%$. São mais altas que no caso de alunos, as proporções de pais que mencionam que não gostariam que homossexuais fossem colegas de escola do seu filho. Tal indicador de rejeição está entre 47,5\%, em 
Id on Line Revista Multidisciplinar e de Psicologia

Id on Line Multidisciplinary and Psycology Journal

Fortaleza, e 22,2\%, em Porto Alegre. Corroborando a tendência antes analisada, os homens são mais preconceituosos, chegando, em Recife, a $60 \%$ e, em Fortaleza, a 59,2\% (ABRAMOVAY et al. 2004, p. 280).

Como podemos perceber a homofobia que está fora da escola, é reproduzida nesse espaço. Como apontam os dados os homens, sejam eles alunos ou pais são mais preconceituosos quando se trata de homossexuais, ou seja, bichas e viados, dentro das salas de aula, deslocando uma ideia de masculinidade viril e dominante. Os LGBTs deslocam e afrontam todos os “[...] componente valorizado pela heteronormatividade e pelos arsenais multifariamente a ela ligados - centrados no adulto, masculino, branco, heterossexual, burguês, física e mentalmente "normal"” (JUNQUEIRA, 2009, p. 14).

As "pedagogias da sexualidade" trabalham no objetivo de proporcionar uma vida nos referenciais heterossexuais, por isso quando há uma violência contra um LGBT no espaço escolar, essa é muitas vezes tomada como uma correção/sanção social por sair da norma e como meio de voltar para ela, assim esse "heteroterrorismo" (BENTO, 2011) muitas vezes inibe e coloca no "armário" as homossexualidades, as travestilidades, as transexualidades, e outras formas de viver as sexualidades para além da heterossexualidade.

Tais situações de heteroterrorismo e homofobia acontecem cotidianamente nas diversas escolas Brasil a fora, sendo tais violências muitas vezes silenciadas e invisibilizadas, ou como dizem as bichas, pais, professores, alunos e alunas todos vivem fazendo a Kátia ${ }^{2}$, o que é um grande problema a ser enfrentado e discutido em todos os espaços sociais, sejam eles públicos ou privados.

\section{A Via(da)gem não vai acabar...}

Na primeira parte do texto nos preocupamos em apresentar como os conceitos de sexo, gênero e sexualidade permearam as ciências biomédicas. Tomamos como marco inicial a virada do século XVIII para o século XIX, mais especificamente a partir dos anos 1850, quando Richard von Krafft-Ebing publicou suas ideias sobre o tema, como bem ressaltado por Weeks (2000). Através dos textos de Preciado (2014) vimos como as ciências biomédicas trataram a

\footnotetext{
${ }^{2}$ Fazer a Kátia na linguagem das bichas significa: ficar cego para uma determinada situação. Tal expressão faz menção à cantora brasileira Kátia, que possui deficiência visual, e fez muito sucesso nos anos 80 . 
Id on Line Revista Multidisciplinar e de Psicologia

Id on Line Multidisciplinary and Psycology Journal

questão a partir dos anos 1955 com os estudos de John Money em relação a crianças nascidas intersexuais, trazendo a baila o debate de uma teoria construtivista social em relação ao sexo e gênero, sendo esta posteriormente formulada e discutida com maior ênfase pelos movimentos sociais feministas.

O olhar do movimento feminista (re)iniciado a partir dos anos de 1960-70 buscaram promover um distanciamento das teorias essencialistas e produziram análises históricas e sociais das relações de sexo, gênero e sexualidade, como foi delineado na segunda parte do texto. A ruptura epistemológica produzida pelos movimentos feministas no século XX deslocando o corpo feminino, como também as feminilidades de uma produção natural para uma produção política produziram novas formas de subjetividades, além de novas atuações sociais dentro do próprio movimento (VALE, 2006).

Dias (1994) aponta como a produção teórica criticou e deslocou estereótipos socialmente construindo e tidos como universalizantes sobre as mulheres, apontando que o feminino foi excluído de um discurso histórico oficial. Scott (1990) apresenta como o conceito de gênero foi utilizado pelas feministas, sendo que em um de seus usos o termo se refere às relações sociais entre os sexos, afastando-se de indicadores biológicos naturalizantes, proporcionando aos pesquisadores a inclusão ou não do sexo nessas análises, não como sendo o fator determinante ou de origem, mas também como uma construção social.

A partir das críticas de Butler (2008) novos atores e atrizes sociais entram em cena, novas sujeitas do feminino surgem para além de uma mulher universal. As reivindicações por determinado gênero sem necessariamente pertencer a um sexo biológico que segue uma ordem inteligível, bio-homem-gênero masculino, bio-mulher-gênero feminino, abala a inteligibilidade do sistema sexo/gênero/desejo, instituído hetero socialmente. O surgimento da Teoria e Movimento Queer e dos Estudos Transviados apresentado na terceira parte do texto foram responsáveis por uma produção do/de conhecimento sobre as experiências dos/as sujeitos/as dissidentes, como também uma crítica ao movimento gay e lésbico instituído dentro de uma heteronormatividade.

Finalizando o texto realizamos um retorno ao pensamento reprodutivista, que junto com as ideias sobre sexo, gênero e sexualidade traçadas anteriormente nos permite subsídios para pensar sobre as violências homofóbicas sofridas por LGBTs nos espaços educacionais, em especial na escola. A existência de tais violências no âmbito escolar podem ser visualizadas nas 
Id on Line Revista Multidisciplinar e de Psicologia

Id on Line Multidisciplinary and Psycology Journal

pesquisas de Abramovay et al. (2004) quando aproximadamente 1/4 dos alunos indicam que não gostariam de ter um colega homossexual, por exemplo.

O espaço da escola é como outros espaços sociais um local de aprendizado das "pedagogias da sexualidade" onde a heteronormatividade - adulta, branca, burguesa e "normal" - é legitima e valorada, produzindo assim heteroterrorismos, inibindo e colocando no "armário" as diversas formas de ser e estar no mundo para além de um modelo heterossexual (LOURO, 2000; JUNQUEIRA, 2009; BENTO, 2011).

Ao leitor desse texto, propomos uma viagem e uma viadagem, mas, essa viagem só tem ponto de partida, enquanto que a viadagem nem tem ponto de partida, nem ponto de chegada, ela é expansiva e surge do big-bang. Expande-se nos gritos de morte dos diversos LGBTs que são assassinados ou violentados no Brasil, expande-se quando uma travesti termina o nível superior em todos os graus, expande-se quando gritamos contra um governo ilegítimo e golpista, expande-se quando lutamos por direitos iguais, expande-se, expande-se e continua expandindo-se, a viadagem e sua potência são possibilidades infinitas...

\section{Referências}

ABRAMOVAY, M. et al. Juventude e sexualidade. Brasília: UNESCO Brasil, 2004.

BENTO, B. Na escola se aprende que a diferença faz a diferença. In: Revista Estudos Feministas, v. 19, n. 2, Florianópolis, 2011.

O que pode uma teoria? Estudos transviados e a despatologização das identidades trans. In: Florestan, n. 2, p. 46, 2014.

BORRILLO, D. Homofobia: história e crítica de um preconceito. Belo Horizonte: Autêntica Editora, 2010.

BOURDIEU, P.; PASSERON, J-C. A reprodução: elementos para uma teoria do sistema de ensino. Rio de Janeiro: Livraria Francisco Alves Editora S.A., 1975.

BUTLER, J. Problemas de gênero: feminismo e subversão da identidade. 2. ed. Rio de Janeiro: Civilização Brasileira, 2008.

DIAS, M. O. L. S. Novas Subjetividades na Pesquisa Histórica Feminista: Uma Hermenêutica das Diferenças. In: Revista Estudos Feministas, v. 2. n. 2, 1994. 
Id on Line Revista Multidisciplinar e de Psicologia

Id on Line Multidisciplinary and Psycology Journal

FACCHINI, R. "Sopa de letrinhas"? - movimento homossexual e produção de identidades coletivas nos anos 90: um estudo a partir da cidade de São Paulo. (Dissertação de Mestrado) Universidade Estadual de Campinas (UNICAMP). Campinas, SP: 2002.

FAUSTO-STERLING, A. Dualismos em Duelo. In: Cadernos Pagu, v. 17-18, p. 9-79, 2002. Los cinco sexos. 1993. Disponível em: < http://www.sigla.org.ar/index.php?option=com_content\&view=article\&id=94\%3Alos-cincosexos1\&Itemid=104 > | https://www.google.com.br/?gws_rd=ssl\# >. Acesso em: 20 Out. 2016.

FRY, P.; MACRAE, E. O que é homossexualidade. São Paulo: Brasiliense, 1985.

GAMSON, J. As sexualidades, a teoria queer e a pesquisa qualitativa. In: DENZIN, N. K.; LINCOLN, Y. S. O planejamento da pesquisa qualitativa: teorias e abordagens. Porto Alegre: Artmed, 2006.

GOMES FILHO, A. S. Estudos Transviados: algumas reflexões. In: Revista Interfaces: saúde, humanas e tecnologia, n. 11, v. 3, 2016.

GOMES FILHO, A. S. et al. "Meninas para um Lado, Meninos para o Outro": Questões de Gênero e Sexualidade na Escola. In: Anais do XV Encontro de Pós-graduação e Pesquisa da Universidade de Fortaleza-UNIFOR. Fortaleza-CE: UNIFOR, 2015.

GOMES FILHO, A. S.; SANTOS, C. E. História da Educação e Teoria QUEER: diálogos possíveis no processo de ensino-aprendizagem. In: Revista do Lhiste, n.3, v.2, jul/dez, 2015.

HOHENDORFF, J. V. Como escrever um artigo de revisão sistemática. In: KOLLER, S. H.; COUTO, M. C. P. P.; HOHENDORFF, J. V. (Orgs.). Manual de produção científica. Porto Alegre: Penso, 2014.

JUNQUEIRA, R. D. Introdução: Homofobia nas Escolas: um problema de todos. In: JUNQUEIRA, R. D. (Org.). Diversidade Sexual na Educação: problematizações sobre a homofobia nas escolas. Brasília: Ministério da Educação, Secretaria de Educação Continuada, Alfabetização e Diversidade, UNESCO, 2009.

LAQUEUR, T. La construción del sexo: cuerpo y género desde los griegos hasta Freud. Madrid: Ediciones Cátedra, 1994.

LE BRETON, D. Antropologia del cuerpo y modernidade. Buenos Aires: Nueva Visión, 2002.

LOURO, G. L. (Org.). O corpo educado: pedagogias da sexualidade. 2. ed. Belo Horizonte: Autêntica Editora, 2000.

Um corpo estranho - ensaio sobre sexualidades e teoria queer. 2. ed. Belo Horizonte: Autêntica, 2015. 
MISKOLCI, R. Teoria Queer: um aprendizado pelas diferenças. 2. ed. Belo Horizonte: Autêntica Editora: UFOP - Universidade Federal de Ouro Preto, 2013.

MOTT, L. AINDA A BARBÁRIE. In: Revista de História da Biblioteca Nacional, 2015.

PADILHA, F.; FACIOLI, L. É O QUEER TEM PRA HOJE? CONVERSANDO SOBRE AS POTENCIALIDADES E APROXIMAÇÕES DA TEORIA QUEER AO SUL DO EQUADOR - ENTREVISTA COM BERENICE BENTO. In: Áskesis, v. 2, n. 1, p. 143-155, Porto Alegre, 2015.

RUBIN, G. Tráfico sexual - entrevista. Gayle Rubin com Judith Butler. In: Cadernos pagu, n. 21. p. 157-209.

SANTOS, B. S.; MENESES, M. P. (Orgs.). Epistemologias do Sul. São Paulo: Editora Cortez, 2010.

\section{SCOTT, J. GÊNERO: UMA CATEGORIA ÚTIL PARA ANÁLISE HISTÓRICA.} Tradução: Dabat, C. R.; Ávila, M. B. 1990.

VALE, A. F. C. O riso da paródia: transgressão, feminismo e subjetividade. In: VALE, A. F. C.; PAIVA, A. C. S. (Orgs.). Estilísticas da sexualidade. Fortaleza: Programa de Pósgraduação em Sociologia da Universidade Federal do Ceará; Campinas: Pontes Editores, 2006.

WEEKS, J. O corpo e a sexualidade. In: LOURO, G. L. (Org.). O corpo educado: pedagogias da sexualidade. 2. ed. Belo Horizonte: Autêntica Editora, 2000.

Como citar este artigo (Formato ABNT):

GOMES FILHO, A.S.; SANTOS, C.E.; SILVA, L.M. Sexo, Gênero, Sexualidade: Via(da)gens em Conceitos. Id on Line Revista Multidisciplinar e de Psicologia, Janeiro de 2017, vol.10, n.33, Supl 2. p. 20-36. ISSN: 19811179.

Recebido: $14 / 12 / 2016$

Aceito: 05/01/2017 